\title{
Research on the Assets Management Systems of Chinese University Shujuan $\mathrm{He}^{1, \mathbf{a}}$ \\ ${ }^{1}$ Department of Assets Loigstic Management of Jilin University, Jilin China \\ an4n4china@126.com
}

Keywords: University, Assets, Management, System, Innovation.

Abstract. In recent years, there are some management problems, which to a certain degree have affected the sustainable and healthy development of Jilin University. The author sums up the research status and characteristic of assets management systems of Jilin University and analysis asset management organization and its functions appraisal system financial system and information management system to give the sugguestion that it is development the Operating Mechanism and the Asset management model for building a harmonious culture of assets management university.

\author{
高校资产管理研究 \\ 贺淑娟 ${ }^{1, a}$ \\ 1吉林大学资产管理与后勤处, 吉林, 中国 \\ an4n4china@126.com
}

关键词: 高校; 资产; 管理; 变迁;

中文摘要. 本文针对吉林大学国有资产的特点及其管理现状, 经过多年实践经验, 发现问题 总结分析, 提出基于制度变迁理论的吉林大学国有资产管理的综合模式。笔者围绕高校资产 管理的组织机构及其功能、绩效考核制度、财务监管制度、算管理制度及高校资产信息化管 理领域等方面进行分析, 为我国高等学校在社会主义市场经济形式下, 对中国特色的高等学 校国有资产管理的模式、运行机制制订并完善提出建议。

\section{1. 高校资产管理的状况}

吉林大学是教育部直属的综合性高校, 是国家重点建设的高水平大学之一。它是由原吉 林大学、吉林工业大学、白求恩医科大学、长春科技大学、长春工业大学和解放军农牧大学 合并而成的全国重点综合性高校。学校合并之初, 各个校区都有自己的资产管理归口部门, 在学校层面、学院层面有资产管理工作职能部门, 并且其工作任务及责任不明确, 存在交叉 管理和管理盲区的现象，形成了各自为政的局面。同时资产归口管理部门亦是资产的监管部 门, 造成了吉林大学各校区的资源缺乏统筹配置和监管，体现在国有资产管理监督与管理无 制衡、管理不规范、配置不合理、整体运营效率不高等问题。

\section{2. 高校资产管理问题原因分析}

首先，问题的根本原因是高校资产管理的体制陈旧，满足不了新的形势发展需要。高校 资源管理的体制改革未能彻底打破，依旧按照老套的模式运行。未对高校资产实行全面统计、 统管且管理机构重叠、办事推委、办事效率低。其次, 高校资产管理制度不完善。没有形成 一套完整的高校资产管理组织机构，在费用使用上存在随意性，缺少有效的监管制度，使预 算在执行过程中偏离计划出现严重的超支或漏洞。另外，高校资源没有形成统一的信息化管 
理平台, 管理混乱落后。设备仪器存在盲目购置, 实验利用不高重复建设。缺失高素质专业 人员管理, 且无合理的绩效考核制度, 员工的工作积极性不高。综上, 问题归根到底是由于 制度变迁动力不足。有关管理人员缺乏制度变迁的意识和动力, 安于现状, 墨守陈规, 而缺 乏对高校资产维护应有的责任心，不愿意制度变迁，难以适应市场经济时代高校资产管理改 革变迁。

\section{3. 应用制度变迁理论实施高校资产管理改革}

针对合校后吉林大学资产管理中出现的问题，迫切需要在高校管理方面理顺管理体制、 建章建制、依章管理。在市场经济时代, 设置科学合理的资产管制度已是迫在眉睫, 笔者依 据政治经济学原理创新提出合适中国特色的高校资产管理制度。

制度变迁是制度的更替、转换及创新的过程。旧的高校资产管理制度的没有形成体系、 不完善。因此高校资产管理制度的变迁是为了实现特定的目标而重新安排制度及重新调整制 度结构的过程。当高校资产管理制度的现状无法满足新时期下高校资产管理需求, 进而产生 了对更高效率制度需求。当高校资产管理的旧制度适应不了新形势的需求, 制度非均衡的情 况就会出现, 此时就有必要推动制度变迁。

另外，高校资产管理制度的制订涉及面广，关系到高校资产的使用效率和健康发展，具有 重要的意义。所以在制订新制度的时候, 要十分谨慎, 会考虑到方方面面的影响, 既要顾及 到吉林大学各个校区的一般性，也要考虑到不同校区的特殊性。

\section{4. 基于制度变迁理论完善高校资产管理对策}

完善高校资产管理制度，要从以下几个方面重新建立并修订制度，保障高校资产功能的 有效发挥。

\section{1 完善高校资产管理的组织机构及功能}

针对当前吉林大学高校资产管理幅度过宽、链条过长以及实施机制不健全的问题, 笔者 建议加强资产管理组织机构的建设, 以吉林大学高校资产管理机构为主, 及以外部中介组织 的管理模式。高校资产行政管理机构。主要职责是制定高校资产管理和经营的方针政策、长 远规划、规章制度决定高校资产的重点发展领域, 制定高校资产经营考核体系负责资产经营 和使用。外部中介机构。其主要职能是负责授权范围内的高校国有资产进行直接的生产和经 营活动。

1、制订高校资产管理的相关法律。采用直接监督及授权等方式来实行监督权力，组织协 调审计、行政监察等部门对高校有资产的使用进行审计和监督。同时为了保障监督的有效性, 需要自行设立或借助外部独立的审计部门和会计事务所, 让其出具有关报告, 作为重要参考。

2、高校应加强资产管理机构建设。对于已经建立的各个校区，则需要进一步完善资产管 理部门的职能, 积极探索新的资产管理方法和模式, 并加强与其他校区之间的合作交流, 吸 取有益的管理经验及模式。

3、加大对高校资产管理人员的投入。特别加强人才及品牌的管理, 改变长期以来资产管理严 重缺失的局面。高校资产管理人员的综合素质直接影响到高校资产的利用效率，因此应注重 对高校资产管理的人力投入, 给予足够的人员配置, 同时加强对资产管理人员的技能培训, 优化其知识结构, 拓展其视野, 让他们充分了解高校资产的相关政策及本部门的实际情况。 


\section{2 完善高校资产管理绩效考核制度}

完善高校资产管理的绩效评价体系, 引入竞争机制。实现对资产管理人员的工作进行科 学合理的评价。只有形成对管理人员强有力的约束, 这样才能有效地对相关管理人员行为进 行有效规范，避免造成因人员因素造成的高校资产损失。

由于高校资产的复杂性和特殊性, 实行绩效评价是难以用具体数字指标衡量的。因此需要运 用一般和特殊方法, 分别采用定量分析与定性分析相结合的方法, 对高校资产管理人员进行 考核。此外, 评价体系要涉及到整个高校资产运行的全过程, 从动态的视角进行整体评价。 绩效评价的指标体系也要实行多元化。要涉及资产管理、预算管理、财务绩效、社会评价等 多维影响因素的整体评价。

\section{3 完善高校资产财务监管制度}

高校资产的特殊性决定需要构建特殊的财务治理模式, 保证高校资产的安全, 推动资产 使用效率的提高。因此必须加大高校内部的财务监管，确保高校资产的健康发展。

第一, 健全学校个校区会计监管组织, 培养高素质的会计专业人才。建立专门针对适合我 国特色的高校国有资产的会计监管组织，加强对各个校区资产的财务监管。

第二, 加大高校资产往来账款的日常管理。对高校日常往来账款的运行情况进行及时分析 与控制, 进行认真总结, 逐步采取相应制度和政策, 预防玩忽职守、舞弊等违法违规行为。 采用实物管理与资金管理相结合方法, 对重点部门和项目的财务开展不定期的审计工作, 明 晰使用单位与个人的财务责任。

第三, 推动财务监管的透明化和信息化。实现财务监管全过程的分级监控, 实行电子账务制 度, 构建账务信息数据库, 保证财务监管的真实性和透明性; 保证能及时反映资产的使用状 况，及时对帐、发现问题，提高工作效率。

\section{4 完善高校资产预算管理制度}

高校的财政拨款要做好预算编制工作，保证预算资金分配的公平性和合理性。申请部门 要将申请预算外资金的理由、数量、使用方向及作用进行详细解释, 并由资产管理部门根据 已有预算资金的使用情况进行决策，同时前将预算草案下达给各校区，广泛征求各校区的意 见，做到预算合理使用。

此外，应当构建严格的预算绩效评价及考核制度。考核结果要与各级部门、个人利益密 切关联, 制定切实可行的评估考核及奖惩机制。具体来说, 首先将预算过程分为编制、批准、 执行、审计和评价等若干阶段，每个阶段设立适合的执行者、评价方法和评价目标。

\section{5 加强高校资产信息化管理}

高校合并后资产管理面临着巨大的工作任务, 需要及时对高校资产登记、管理。资产管 理信息化可以将房屋、车辆、土地及知识产权等有形及无形资产的一切有关信息统计、登记、 管理。先进的高校资源信息管理平台可以合理有效地利用高校的资源，提供资源利用效率。 因此必须构建高校资产数据库及信息管理系统, 同时要大力发展高校资产管理的信息化, 健 康完善的高校资产数据系统为管理决策提供支撑。

以数据库为基础, 利用先进的计算机技术与网络技术, 研发集数据查询、分析、预测等功能 为一身的信息管理系统, 实现集中与远程监管, 对高校资产进行全方位的动态监控, 提高资 产使用效率。例如仪器名称、数量、技术参数、金额、购置、调剂、报废、等信息, 输入数 据库系统, 分门别类, 为日常监管提供及时、有效、全面的信息。具体方法可以采取条码技 术, 将各种非经营性国有资产进行统一编号, 贴上识别码, 与具体资产一一对应, 通过扫描 标识码就可以对资产相关信息一目了然。 


\section{5. 结束语}

长期以来，高校资产管理存在多头管理问题，导致国有资产管理理论及实践研究不能满 足其健康发展的需要, 突出表现在制度建设上在理论与实践的严重滞后, 尚未形成一套科学 完善的高校国有资产管理制度理论体系及实践经验。笔者基于制度变迁理论，分析问题原来， 找到解决途径，建立适合中国社会主义高校特色的国有资产管理制度的对策，塑造高校国有 资产管理文化。为我国高等学校适应社会主义市场经济形式, 建设有中国特色的高等学校国 有资产管理模式、运行机制、及管理指明了方向。

\section{References}

[1] James Mahoney. Path Dependence in Historical Sociology [J]. Theory and Society, 2000 (29).

[2] Lin Yifu. An Economic Theory of Institutional Change : Induced and Imposed Change [J]. Cato J, 1990, $9(1)$.

[3] Ross, S. The Eeonolnie Theory of Agency : The PrinciPals' Problem[J]. Ameriean Economic Review, 1973 (63).

[4] Furbotn, E. Pejovich, S. Property Rights and Economic Theory : A Survey of Recent Literature[J]. Journal of Economic Literature, Dec. 1972.

[5] Begot. Holm strom and Pau l M ilgrom, 1991, Multi-task Principal-agent analyses : incentives con-tracts, asset ownership and job design. Journal of Law, Economics and organ ization.

[6] Stephen A Ross . The Economic Theory of Agency : The Principal's Problem. The American Economist. 1973. 